\title{
Strength Evaluation of Reinforced Concrete Structure for Regular Building due to Earthquake Load Based on Different Soil Types
}

\author{
Jonie Tanijaya ${ }^{1^{*}}$, Robby Kwandou ${ }^{2}$ \\ ${ }^{1}$ Department of Civil Engineering, UKIP, INDONESIA \\ ${ }^{2}$ Department of Civil Engineering, Universitas Hasanuddin, INDONESIA \\ *Corresponding author : jonie.tanijaya@gmail.com
}

\begin{abstract}
Earthquakes are natural events caused by tectonic plate movements and it is unpredictable. Thus, the building design regulation has an important role in ensuring the Earthquake resistant structure. A commonly used method is the response spectrum method. For different soil types, the value of the design spectra may increase or decrease. Therefore this study aims to determine the effect of soil type on the strength of reinforced concrete structures, especially the building behavior and structural internal forces. Analysis results show that the increase of base-shear value of Makassar is about $34 \%$ and $103 \%$ for medium soil and soft soil condition compared to hard soil. The increase of beam negative moment is about $27 \%$ to $39 \%$ in soft soil compared to hard soil, while the value is about $8 \%$ to $14 \%$ in medium soil compared to hard soil. The increase of beam positive moment varies considerably between $8 \%$ to $50 \%$. The increasing moment is directly proportional to the required reinforcement area of the beam. Demand capacity ratio of column has also increased about $10 \%$ to $35 \%$ for medium soil and soft soil compared to hard soil.
\end{abstract}

KEYWORDS Soil type; Seismic; Reinforced concrete

(C) The Author(s) 2018. This article is distributed under a Creative Commons Attribution-ShareAlike 4.0 International license.

\section{INTRODUCTION}

Earthquakes are natural events caused by tectonic plate movements and it is unpredictable (Soelarso, Baehaki and Novtikania, 2016). This phenomenon begins with a clash of plates in the Earth's crust that directly makes the building on the Earth's surface vibrate. This vibration may develop the internal force in the building due to its stiffness to resist vibration. Excessive vibration can cause severe damage and even further the collapse of the building. Therefore, the shock caused by the movement of tectonic plates is one of the main causes of structural damage. Indonesia is an area prone to earthquakes due to its geographical location at the meeting of four major tectonic plates of Eurasia, Indo-Australia, the Pacific and the Philippines (Hasan and Astira, 2013). This results in a highintensity earthquake in Indonesia.

Thus, the regulation for earthquake-resistant building has a major role in ensuring the building safety. In the last decade, the damage caused by the earthquake has exceeded the predictions of the Indonesian building regulations. Severe building damage has been occurred in Aceh, Yogyakarta, and Padang due to the unpredicted large force earthquake. This is influenced by the increase of peak ground acceleration which is greater than the value in Indonesian code SNI
1726:2002. Therefore there is a need to revise the code from SNI 1726:2002 to SNI 1726:2012 (National Standardization Agency, 2012).

The variation of peak ground acceleration due to the changes in earthquake code resulted in varying seismic load for each region in Indonesia (Cornelis, Bunganaen and Tay, 2014). In addition, the effect of vertical seismic load in SNI 1726:2012 also needs to be included in calculations, in contrast to SNI 1726:2002 which is optional only. The legitimation of SNI 1726:2012 means that all the buildings should be planned by using the new regulations.

The earthquake force is affected by the soil type. The fast movement on the ground due to soil vibration will lead to larger deformation in buildings especially in soft soil cases (Jingga, Suryanita and Yuniarto, 2015). Excessive building deformation will cause even sudden collapse of the building. The higher building will have larger displacement due to larger deformation. The seismic force is the base shear force that acts on the base of the building and will be distributed vertically along the height of the structure as the horizontal story force (Faizah and Widodo, 2013).

Story shear is gained by summing the horizontal story forces. One of the most commonly used methods in 
SNI 1726:2012 is the response spectrum method. Generally, in this method, the soil classification is divided into three types. There are hard soil (SC), medium soil (SD) and soft soil (SE). For different soil types, the value of the design spectra may increase or decrease (Arfiadi and Satyarno, 2013). This variation of the design leads to the changes of either the internal force or seismic force distribution values. But the question about the effect of soil types in seismic force has not been fully answered. In addition, the impact on the design of structural strength is also questioned.

Reinforced concrete structure is a commonly used structure in Indonesia construction. The concept of earthquake-resistant building is the structure should not collapse due to strong earthquakes (nominal earthquake) and should have the ability to dissipate the seismic loads (Sudarsana and Yudha, 2014). It is also well-known as the capacity design method. In this method, the structural elements which will yield first should be determined (weak element). These elements will undergo plastification (damage) first in order to anticipate earthquake energy in the structure. Therefore, structural ductility plays an important role.

Other structural elements that do not undergo plastification should still behave elastically during strong earthquakes. In SNI 2847-2013 (National Standardization Agency, 2013b) this concept is fully described in the requirements of Special Moment Resisting Frame (SMRF) (Imran and Hendrik, 2010). SMRF has the highest ductility and should be used in earthquake-prone areas. Therefore this study aims to determine the effect of soil type on the strength of reinforced concrete structures, in this case to review the building behavior and the internal forces.

\section{RESEARCH METHODS}

The function of the building as an office and located in Makassar. The live load value is $240 \mathrm{~kg} / \mathrm{m}^{2}$ based on SNI 1727:2013 (National Standardization Agency, 2013a). Seismic force analysis is based on SNI 1726:2012 while the reinforced concrete analysis is based on SNI $2847: 2013$. The building is a reinforced concrete structure with a height variation of 5 -stories building $+\operatorname{roof}(\mathrm{h}=19.30 \mathrm{~m}), 8$-stories $+\operatorname{roof}(\mathrm{h}=30.40 \mathrm{~m})$ and 10 -stories $+\operatorname{roof}(\mathrm{h}=37.80 \mathrm{~m})$.

Each building was analyzed with seismic load for hard soil (SC), medium soil (SD) and soft soil (SE). The lateral system is the Special Moment Resisting Frame (SMRF). Structural plan is typical for entire floors, except for roof (Figure 1). The structural model was analyzed by using ETABS program. The 3D model of the building is illustrated in Figure 2 .
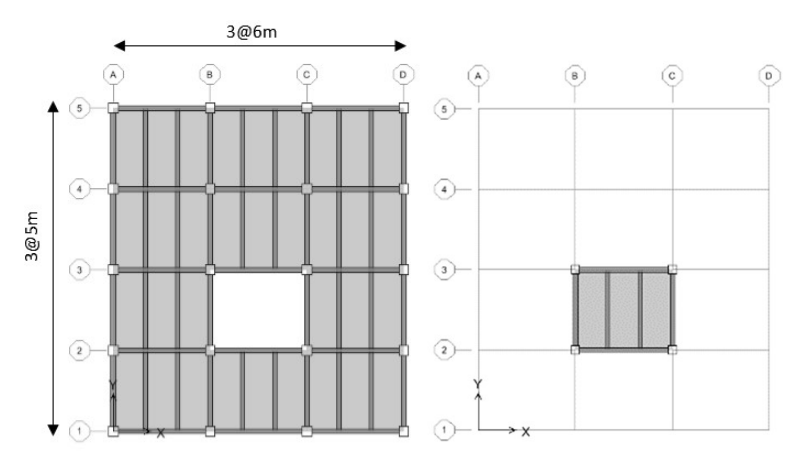

Figure 1. Floor and roof plan.
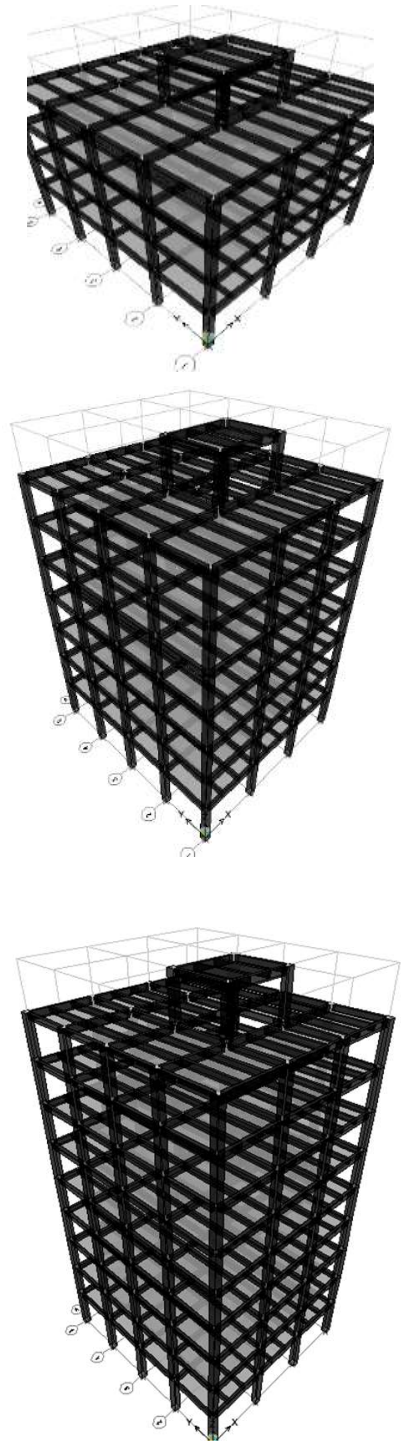

Figure 2. 3D model for 5-stories, 8-stories and 10-stories.

The primary beam dimension is typical for the all structural models. Beam $300 \mathrm{~mm}$ x $600 \mathrm{~mm}$ is used for $6 \mathrm{~m}$ span and $300 \mathrm{~mm} \times 500 \mathrm{~mm}$ for $5 \mathrm{~m}$ span. The secondary beam dimension is also typically $250 \mathrm{~mm} \mathrm{x}$ 
$500 \mathrm{~mm}$. The column dimensions are $500 \mathrm{~mm} \times 500$ $\mathrm{mm}, 550 \mathrm{~mm} \times 550 \mathrm{~mm}$ and $600 \mathrm{~mm} \times 600 \mathrm{~mm}$ sequentially for the 5 -stories, 8 -stories and 10-stories model. Slab thickness is typically $120 \mathrm{~mm}$. Concrete strength is $\mathrm{f}^{\prime} \mathrm{c}=25 \mathrm{MPa}$ and rebar strength is BJTS40 (fy $=390 \mathrm{MPa}$ ). The design response spectrum is illustrated in Figure 3.

Figures 4 and 5 show the difference of spectral acceleration for short period (SDS) and 1 second (SD1) Response Spectrum

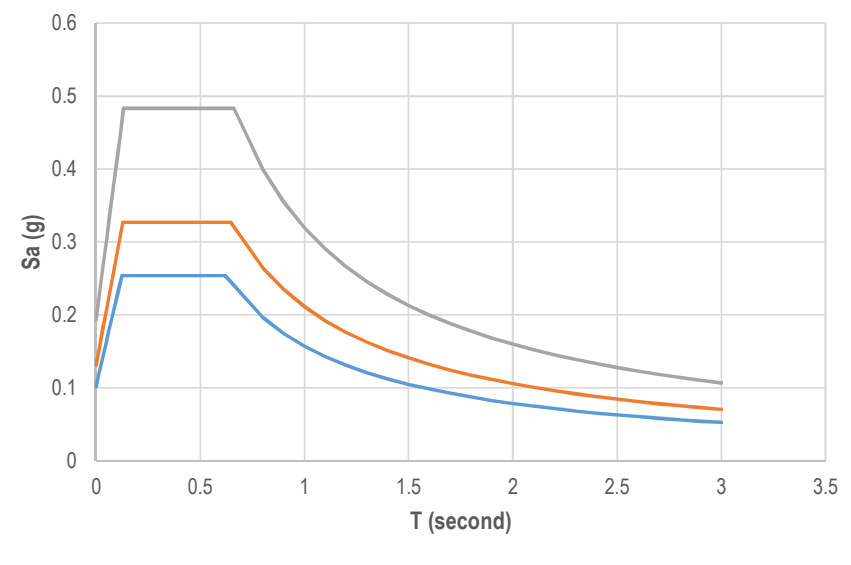

_Hard Soil —Medium Soil — Soft Soil

Figure 3. Response spectrum for Makassar with three soil types.

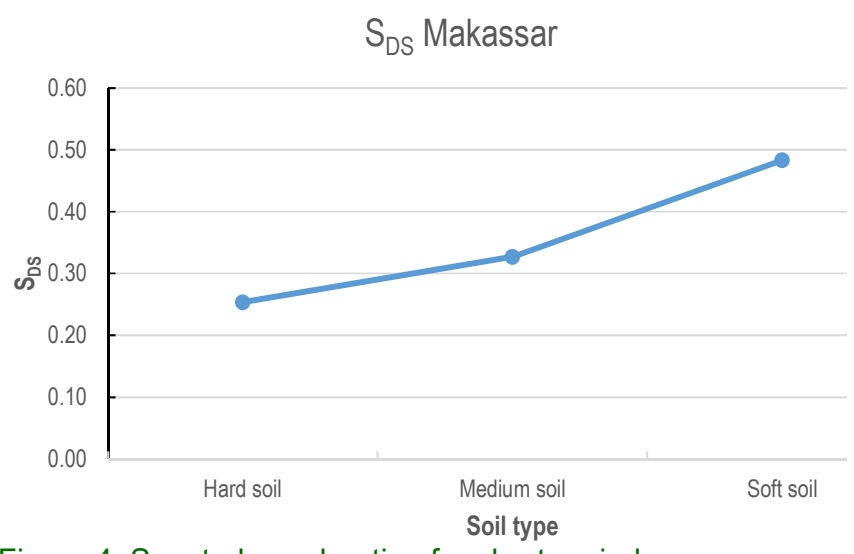

Figure 4. Spectral acceleration for short period.

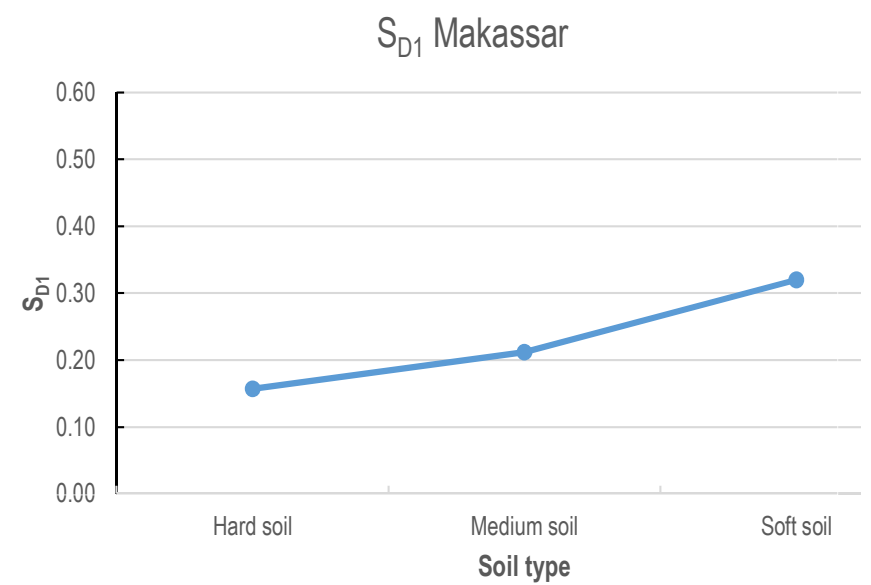

Figure 5. Spectral acceleration for 1 second period. period for all three soil types. The difference of SDS values for medium and soft soils are $28.92 \%$ and $90.58 \%$ compared to hard soil. While the difference of SD1 values for medium soil and soft soil are $34.62 \%$ and $103.50 \%$ compared to hard soil. This difference is quite high, especially when comparing the hard soil to soft soil. It certainly has an impact on the magnitude of the seismic load in the building.

\section{RESULTS AND DISCUSSION}

Analysis results show that the static base-shear for both $\mathrm{X}$ and $\mathrm{Y}$ directions are controlled by the minimum value of vibration period so that the value is the same for both directions. The dynamic base-shear should have a minimum value of $85 \%$ static base-shear. In this case, the seismic load values for all models need to be scaled back by using the scale factor $0.85 \mathrm{~V}_{\text {static }} / \mathrm{V}_{\text {dynamic }}$. The maximum difference of scale factor between soft soil compared to hard soil is $0.28 \%, 0.90 \%$ and $6.78 \%$ for 10 -stories, 8 -stories and 5 -stories buildings, while for the medium soil is $0.18 \%, 0.61 \%$ and $4.44 \%$ for 10 stories, 8 -stories and 5 -stories buildings. It can be seen that the smaller difference of the scale factor for different soil types could be found as the increasing of building height (Table 1). Thus the effect of different soil types tends to be insignificant to the dynamic scale factor $\left(V_{\text {static }} / V_{\text {dynamic }}\right)$ for higher building. In contrast to lower buildings, soft soil tend to produce larger scale factor compared to hard soil $(6.78 \%$ for 5 -stories buildings).

The story shear result can be seen in Figure 6. The graph curvature becomes smaller as the soil becomes harder. It is influenced by the smaller base-shear value when the soil become harder so that the distribution of seismic load to each level also decreases. It could be also seen that the percentage difference of building maximum displacement is directly proportional to the base shear of the building (Table 2).

Table 1. Scale factor and base-shear for 10-stories, 8stories and 5-stories buildings.

\begin{tabular}{llllll}
\hline $\begin{array}{l}\text { Total } \\
\text { stories }\end{array}$ & $\begin{array}{l}\text { Soil } \\
\text { type }\end{array}$ & \multicolumn{2}{c}{ Scale Factor-X } & \multicolumn{2}{c}{ Scale Factor-Y } \\
\hline \multirow{3}{*}{10} & Hard* & 2.351 & $0.00 \%$ & 2.595 & $0.00 \%$ \\
& Medium & 2.354 & $0.14 \%$ & 2.600 & $0.18 \%$ \\
& Soft & 2.356 & $0.21 \%$ & 2.602 & $0.28 \%$ \\
8 & Hard* & 2.240 & $0.00 \%$ & 2.482 & $0.00 \%$ \\
& Medium & 2.254 & $0.61 \%$ & 2.488 & $0.26 \%$ \\
& Soft & 2.260 & $0.90 \%$ & 2.491 & $0.37 \%$ \\
& Hard* & 2.789 & $0.00 \%$ & 2.824 & $0.00 \%$ \\
5 & Medium & 2.913 & $4.44 \%$ & 2.950 & $4.44 \%$ \\
& Soft & 2.978 & $6.78 \%$ & 3.016 & $6.78 \%$ \\
\hline
\end{tabular}


Table 2. Maximum displacement

\begin{tabular}{llllll}
\hline $\begin{array}{l}\text { Total } \\
\text { stories }\end{array}$ & $\begin{array}{l}\text { Soil } \\
\text { type }\end{array}$ & \multicolumn{2}{c}{$\begin{array}{l}\text { Max X-disp } \\
(\mathrm{mm})\end{array}$} & \multicolumn{2}{c}{$\begin{array}{l}\text { Max Y-disp } \\
(\mathrm{mm})\end{array}$} \\
\hline \multirow{3}{*}{10} & Hard* & 19.80 & $0.00 \%$ & 27.72 & $0.00 \%$ \\
& Medium & 26.65 & $34.61 \%$ & 37.31 & $34.58 \%$ \\
& Soft & 40.29 & $103.48 \%$ & 56.29 & $103.03 \%$ \\
8 & Hard* & 15.24 & $0.00 \%$ & 21.88 & $0.00 \%$ \\
& Medium & 20.60 & $35.17 \%$ & 29.37 & $34.21 \%$ \\
& Soft & 31.28 & $105.22 \%$ & 44.51 & $103.39 \%$ \\
5 & Hard* & 11.51 & $0.00 \%$ & 16.17 & $0.00 \%$ \\
& Medium & 15.76 & $36.94 \%$ & 22.49 & $39.14 \%$ \\
& Soft & 23.78 & $106.62 \%$ & 34.67 & $114.45 \%$ \\
\hline
\end{tabular}

*hard soil as reference value for percentage calculation
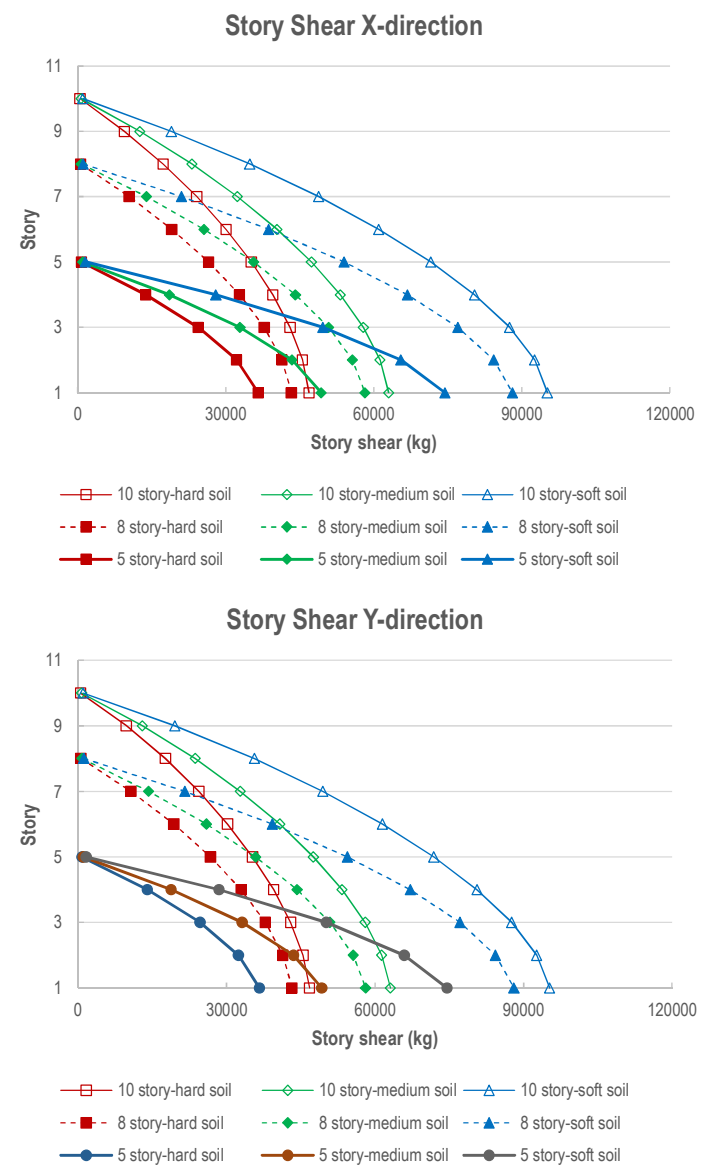

Figure 6. Story shear for $X$ and $Y$ direction.

Differences in base-shear values due to different soil types tend to be almost the same (less than $5 \%$ ) for all models. This indicates that the difference of building height does not affect the proportion of base-shear values for different soil types. The increase of beam negative moment for B30x60 in soft soil is $28.26 \%$, $27.10 \%$ and $28.95 \%$ compared to hard soil for 10 stories, 8-stories and 5-stories building respectively (Table 3), while for medium soil is $9.60 \%, 8.67 \%$ and $10.13 \%$. The increase of beam negative moment for B30x50 in soft soil is $36.39 \%, 34.67 \%$ and $38.80 \%$ compared to hard soil for 10-stories, 8-stories and 5- stories building respectively, while for medium soil is $12.35 \%, 11.62 \%$ and $13.37 \%$ (Table 4 ). It can be concluded that the increase of beam negative moment is about $27 \%$ to $39 \%$ in soft soil compared to hard soil, while for medium soil is about $8 \%$ to $14 \%$.

Table 3. Ultimate moment and rebar areas B30x60.

\begin{tabular}{|c|c|c|c|c|c|c|}
\hline \multirow{2}{*}{$\begin{array}{l}\text { Total } \\
\text { stories }\end{array}$} & \multirow{2}{*}{ Soil type } & \multirow{2}{*}{$\begin{array}{l}\text { positive/ } \\
\text { negative }\end{array}$} & \multicolumn{4}{|c|}{ B30x60 } \\
\hline & & & \multicolumn{2}{|c|}{$\begin{array}{l}\text { Ultimate moment } \\
\text { (t.m) }\end{array}$} & \multicolumn{2}{|c|}{$\mathrm{A}_{s}\left(\mathrm{~mm}^{2}\right)$} \\
\hline \multirow[t]{7}{*}{10} & \multirow[t]{2}{*}{ Hard $^{*}$} & pos & 10.60 & $0.00 \%$ & 573 & $0.00 \%$ \\
\hline & & neg & 17.62 & $0.00 \%$ & 964 & $0.00 \%$ \\
\hline & \multirow[t]{2}{*}{ Medium } & pos & 10.60 & $0.00 \%$ & 573 & $0.00 \%$ \\
\hline & & neg & 19.31 & $9.60 \%$ & 1063 & $10.27 \%$ \\
\hline & \multirow[t]{3}{*}{ Soft } & pos & 11.45 & $8.08 \%$ & 614 & $7.16 \%$ \\
\hline & & neg & & 28.26 & & \\
\hline & & & 22.60 & $\%$ & 1259 & $30.60 \%$ \\
\hline \multirow[t]{7}{*}{8} & \multirow[t]{2}{*}{ Hard* } & pos & 10.87 & $0.00 \%$ & 581 & $0.00 \%$ \\
\hline & & neg & 17.32 & $0.00 \%$ & 947 & $0.00 \%$ \\
\hline & \multirow[t]{2}{*}{ Medium } & pos & 10.87 & $0.00 \%$ & 581 & $0.00 \%$ \\
\hline & & neg & 18.82 & $8.67 \%$ & 1034 & $9.19 \%$ \\
\hline & \multirow[t]{3}{*}{ Soft } & pos & 11.78 & $8.40 \%$ & 632 & $8.78 \%$ \\
\hline & & neg & & 27.10 & & \\
\hline & & & 22.01 & $\%$ & 1224 & $29.25 \%$ \\
\hline \multirow[t]{9}{*}{5} & \multirow[t]{2}{*}{ Hard* $^{*}$} & pos & 11.24 & $0.00 \%$ & 602 & $0.00 \%$ \\
\hline & & neg & 18.92 & $0.00 \%$ & 1040 & $0.00 \%$ \\
\hline & \multirow[t]{3}{*}{ Medium } & pos & 11.56 & $2.88 \%$ & 620 & $2.99 \%$ \\
\hline & & neg & & 10.13 & & \\
\hline & & & 20.83 & $\%$ & 1153 & $10.87 \%$ \\
\hline & \multirow[t]{4}{*}{ Soft } & pos & & 16.61 & & \\
\hline & & & 13.10 & $\%$ & 706 & $17.28 \%$ \\
\hline & & neg & & 28.95 & & \\
\hline & & & 24.39 & $\%$ & 1368 & $31.54 \%$ \\
\hline
\end{tabular}

*hard soil as reference value for percentage calculation

Table 4. Ultimate moment and rebar areas B30x50.

\begin{tabular}{lllllll}
\hline $\begin{array}{l}\text { Total } \\
\text { storie }\end{array}$ & Soil & type & positive/ & \multicolumn{4}{c}{ B30x50 } \\
$\mathrm{s}$ & & negative & \multicolumn{3}{l}{ Ultimate } \\
moment (t.m) & $\mathrm{A}_{\mathrm{s}}\left(\mathrm{mm}^{2}\right)$ \\
\hline 10 & Hard* & pos & 6.69 & $0.00 \%$ & 477 & $0.00 \%$ \\
& & neg & 10.81 & $0.00 \%$ & 705 & $0.00 \%$ \\
& Medium & pos & 6.69 & $0.00 \%$ & 477 & $0.00 \%$ \\
& & neg & 12.15 & $12.35 \%$ & 797 & $13.05 \%$ \\
& Soft & pos & 8.19 & $22.33 \%$ & 608 & $27.46 \%$ \\
& & neg & 14.75 & $36.39 \%$ & 981 & $39.15 \%$ \\
8 & Hard* & pos & 6.76 & $0.00 \%$ & 477 & $0.00 \%$ \\
& & neg & 10.86 & $0.00 \%$ & 709 & $0.00 \%$ \\
& Medium & pos & 6.76 & $0.00 \%$ & 477 & $0.00 \%$ \\
& & neg & 12.13 & $11.62 \%$ & 796 & $12.27 \%$ \\
& Soft & pos & 7.95 & $17.58 \%$ & 601 & $26.00 \%$ \\
& & neg & 14.63 & $34.67 \%$ & 973 & $37.24 \%$ \\
& \multirow{2}{*}{ Hard* } & pos & 6.86 & $0.00 \%$ & 477 & $0.00 \%$ \\
& & neg & 11.18 & $0.00 \%$ & 730 & $0.00 \%$ \\
& Medium & pos & 6.86 & $0.00 \%$ & 478 & $0.21 \%$ \\
& & neg & 12.67 & $13.37 \%$ & 834 & $14.25 \%$ \\
& Soft & pos & 10.31 & $50.35 \%$ & 752 & $57.65 \%$ \\
& & neg & 15.52 & $38.80 \%$ & 1036 & $41.92 \%$ \\
\hline
\end{tabular}

*hard soil as reference value for percentage calculation

The increase of beam positive moment for B30x60 in soft soil is $8.08 \%, 8.40 \%$ and $16.61 \%$ compared to hard soil for 10 -stories, 8 -stories and 5 -stories building respectively, while for medium soil is $0.00 \%, 0.00 \%$ and 
$2.88 \%$. The increase of beam positive moment for B30x50 in soft soil is $22.33 \%, 17.58 \%$ and $50.35 \%$ compared to hard soil for 10-stories, 8-stories and 5stories building respectively, while for medium soil does not change. It can be seen that the increasing pattern of the beam negative moment tends to be almost the same (Figure 7), while the increasing pattern of beam positive moment is different, especially for 5-stories building (Figure 8). It is influenced by the difference in seismic scale factor that is quite visible in the 5-stories building, as stated before. As for the negative moment, this difference

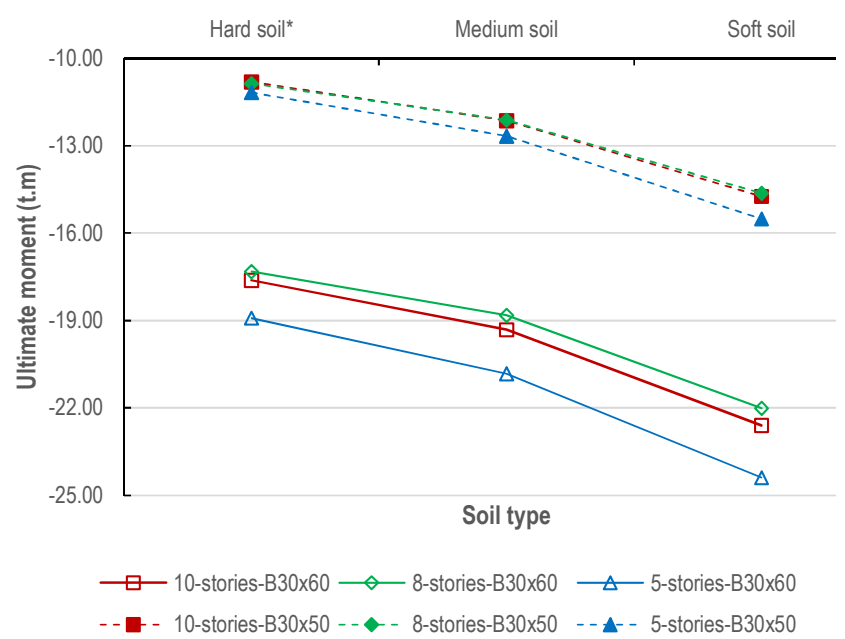

Figure 7. Beam negative moment.

Table 5. The converted diameter and rebar amount B30x60

\begin{tabular}{|c|c|c|c|c|c|}
\hline \multirow{2}{*}{$\begin{array}{l}\text { Total } \\
\text { stories }\end{array}$} & \multirow{2}{*}{$\begin{array}{l}\text { Soil } \\
\text { type }\end{array}$} & \multirow[t]{2}{*}{ pos/neg } & \multicolumn{3}{|c|}{ B30x60 } \\
\hline & & & $\begin{array}{l}A_{s \text { req }} \\
\left(\mathrm{mm}^{2}\right)\end{array}$ & $\begin{array}{l}\text { Rebar } \\
\text { use }\end{array}$ & $\mathrm{A}_{\mathrm{s}}\left(\mathrm{mm}^{2}\right)$ \\
\hline \multirow[t]{6}{*}{10} & \multirow{2}{*}{ Hard* } & positive & 573 & 3D16 & 603.19 \\
\hline & & negative & 964 & 5D16 & 1005.31 \\
\hline & \multirow{2}{*}{ Medium } & positive & 573 & 3D16 & 603.19 \\
\hline & & negative & 1063 & 6D16 & 1206.37 \\
\hline & \multirow{2}{*}{ Soft } & positive & 614 & 4D16 & 804.25 \\
\hline & & negative & 1259 & 7D16 & 1407.43 \\
\hline \multirow[t]{6}{*}{8} & \multirow{2}{*}{ Hard* } & positive & 581 & 3D16 & 603.19 \\
\hline & & negative & 947 & $5 \mathrm{D} 16$ & 1005.31 \\
\hline & \multirow{2}{*}{ Medium } & positive & 581 & 3D16 & 603.19 \\
\hline & & negative & 1034 & 6D16 & 1206.37 \\
\hline & \multirow{2}{*}{ Soft } & positive & 632 & 4D16 & 804.25 \\
\hline & & negative & 1224 & 7D16 & 1407.43 \\
\hline \multirow[t]{6}{*}{5} & \multirow{2}{*}{ Hard $^{*}$} & positive & 602 & 3D16 & 603.19 \\
\hline & & negative & 1040 & 6D16 & 1206.37 \\
\hline & \multirow{2}{*}{ Medium } & positive & 620 & 4D16 & 804.25 \\
\hline & & negative & 1153 & 6D16 & 1206.37 \\
\hline & \multirow{2}{*}{ Soft } & positive & 706 & 4D16 & 804.25 \\
\hline & & negative & 1368 & 7D16 & 1407.43 \\
\hline
\end{tabular}

*hard soil as reference value for percentage calculation does not seem to be changing significantly because of the effect of gravity moments at the support area.

The difference of longitudinal rebar area is directly proportional to the moment (Table 3 and Table 4). Table 5 and 6 shows the converted diameter and rebar amount. It can be seen that the increase in the number of rebar is about 1 to 2 rebars. The stirrup rebar area for shear reinforcing is then calculated based on the used longitudinal rebar using capacity design method (Table 7 and 8 ). It can be seen that the maximum difference between the stirrup rebar areas is about $15.00 \%$ for soft soil compared to hard soil.

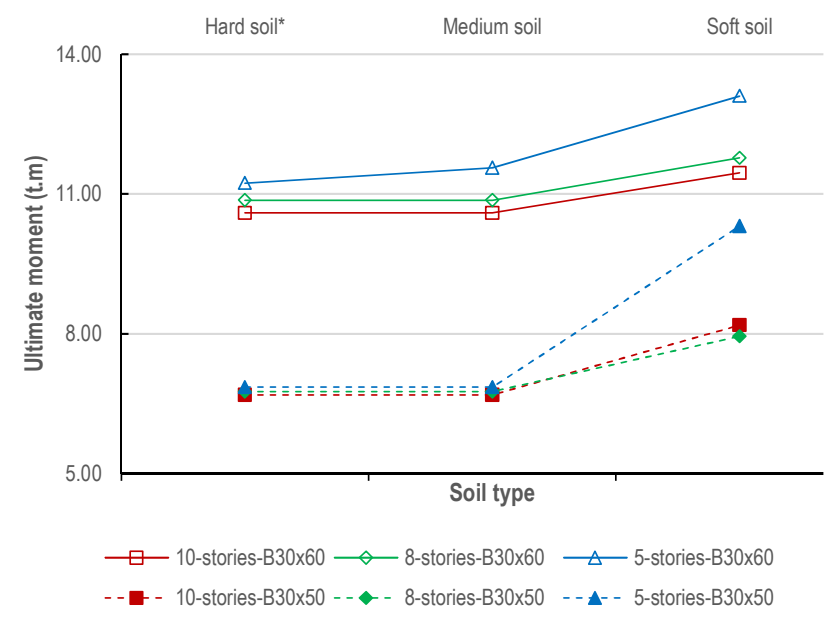

Figure 8. Beam positive moment.

Table 6. The converted diameter and rebar amount B30x50.

\begin{tabular}{|c|c|c|c|c|c|}
\hline \multirow{2}{*}{$\begin{array}{l}\text { Total } \\
\text { stories }\end{array}$} & \multirow{2}{*}{$\begin{array}{l}\text { Soil } \\
\text { type }\end{array}$} & \multirow[t]{2}{*}{ pos/neg } & \multicolumn{3}{|c|}{$\mathrm{B} 30 \times 50$} \\
\hline & & & $\begin{array}{l}A_{s \text { req }} \\
\left(\mathrm{mm}^{2}\right)\end{array}$ & $\begin{array}{l}\text { Rebar } \\
\text { use }\end{array}$ & $\mathrm{A}_{\mathrm{s}}\left(\mathrm{mm}^{2}\right)$ \\
\hline \multirow[t]{6}{*}{10} & \multirow{2}{*}{ Hard* } & positive & 477 & 3D16 & 603.19 \\
\hline & & negative & 705 & $4 \mathrm{D} 16$ & 804.25 \\
\hline & \multirow{2}{*}{ Medium } & positive & 477 & 3D16 & 603.19 \\
\hline & & negative & 797 & 4D16 & 804.25 \\
\hline & \multirow{2}{*}{ Soft } & positive & 608 & $4 \mathrm{D} 16$ & 804.25 \\
\hline & & negative & 981 & 5D16 & 1005.31 \\
\hline \multirow[t]{6}{*}{8} & \multirow{2}{*}{$\operatorname{Hard}^{*}$} & positive & 477 & 3D16 & 603.19 \\
\hline & & negative & 709 & 4D16 & 804.25 \\
\hline & \multirow{2}{*}{ Medium } & positive & 477 & 3D16 & 603.19 \\
\hline & & negative & 796 & $4 \mathrm{D} 16$ & 804.25 \\
\hline & \multirow{2}{*}{ Soft } & positive & 601 & 3D16 & 603.19 \\
\hline & & negative & 973 & 5D16 & 1005.31 \\
\hline \multirow[t]{6}{*}{5} & \multirow{2}{*}{ Hard* } & positive & 477 & 3D16 & 603.19 \\
\hline & & negative & 730 & 4D16 & 804.25 \\
\hline & \multirow{2}{*}{ Medium } & positive & 478 & 3D16 & 603.19 \\
\hline & & negative & 834 & $5 \mathrm{D} 16$ & 1005.31 \\
\hline & \multirow{2}{*}{ Soft } & positive & 752 & $4 \mathrm{D} 16$ & 804.25 \\
\hline & & negative & 1036 & $6 \mathrm{D} 16$ & 1206.37 \\
\hline
\end{tabular}

*hard soil as reference value for percentage calculation 
Table 7. Stirrup rebar area B30x60.

\begin{tabular}{lllll}
\hline $\begin{array}{l}\text { Total } \\
\text { stories }\end{array}$ & Soil type & Stirrup used & \multicolumn{3}{c}{$\mathrm{B} 30 \times 60$} \\
$\mathrm{~A}_{\mathrm{vs}} / \mathrm{s}\left(\mathrm{mm}^{2} / \mathrm{mm}\right)$
\end{tabular}

*hard soil as reference value for percentage calculation
Table 8. Stirrup rebar area B30x50.

\begin{tabular}{llccc}
\hline $\begin{array}{l}\text { Total } \\
\text { stories }\end{array}$ & Soil type & \multicolumn{3}{c}{$\mathrm{B} 30 \times 50$} \\
\hline 10 & Stirrup used & \multicolumn{2}{c}{$\mathrm{A}_{\mathrm{vs}} / \mathrm{s}\left(\mathrm{mm}^{2} / \mathrm{mm}\right)$} \\
& Medium & 2D10-110 & 1.43 & $0.00 \%$ \\
& 2D10-110 & 1.43 & $0.00 \%$ \\
8 & Soft & 2D10-100 & 1.57 & $10.00 \%$ \\
& Hard* & 2D10-110 & 1.43 & $0.00 \%$ \\
& Medium & 2D10-110 & 1.43 & $0.00 \%$ \\
5 & Soft & 2D10-105 & 1.50 & $4.76 \%$ \\
& Hard* & 2D10-110 & 1.43 & $0.00 \%$ \\
& Medium & 2D10-105 & 1.50 & $4.76 \%$ \\
& Soft & 2D10-100 & 1.57 & $10.00 \%$ \\
\hline
\end{tabular}

*hard soil as reference value for percentage calculation

Table 9 shows the demand capacity ratio $(\mathrm{D} / \mathrm{C})$ of column based on the Strong Column Weak Beam (SCWB) concept.

Table 9. Demand capacity ratio of column (Strong Column Weak Beam).

\begin{tabular}{|c|c|c|c|c|c|c|}
\hline Total stories & Soil type & Column dimension (mm x mm) & $1.2 \Sigma \mathrm{M}_{\text {beam }}(\mathrm{t} . \mathrm{m})$ & $\Sigma \mathrm{M}_{\mathrm{col}}(\mathrm{t} . \mathrm{m})$ & $\mathrm{D} / \mathrm{C}_{1}$ & \\
\hline \multirow{3}{*}{10} & Hard* & \multirow{3}{*}{$\begin{array}{l}600 \times 600 \\
(16 \mathrm{D} 19)\end{array}$} & 34.14 & 82.20 & 0.42 & $0.00 \%$ \\
\hline & Medium & & 38.05 & 82.20 & 0.46 & $11.46 \%$ \\
\hline & Soft & & 45.98 & 82.20 & 0.56 & $34.69 \%$ \\
\hline \multirow{3}{*}{8} & Hard* & \multirow{3}{*}{$\begin{array}{l}550 \times 550 \\
(12 \mathrm{D} 19)\end{array}$} & 34.14 & 64.20 & 0.53 & $0.00 \%$ \\
\hline & Medium & & 38.05 & 64.20 & 0.59 & $11.46 \%$ \\
\hline & Soft & & 45.98 & 64.20 & 0.72 & $34.69 \%$ \\
\hline \multirow{3}{*}{5} & Hard $^{*}$ & \multirow{3}{*}{$\begin{array}{l}500 \times 500 \\
(12 \mathrm{D} 16)\end{array}$} & 38.05 & 59.00 & 0.64 & $0.00 \%$ \\
\hline & Medium & & 42.18 & 59.00 & 0.71 & $10.85 \%$ \\
\hline & Soft & & 45.98 & 59.00 & 0.78 & $20.85 \%$ \\
\hline
\end{tabular}

*hard soil as reference value for percentage calculation

It can be seen that the $\mathrm{D} / \mathrm{C}$ ratio of the column for medium soil and soft soil increase about $11.46 \%$ and $34.69 \%$ compared to hard soil. Both values are the same for the 10-stories and 8 -stories buildings because the used longitudinal rebar is the same. As for the 5storey building $\mathrm{D} / \mathrm{C}$ ratio increase by $10.85 \%$ and $20.85 \%$ respectively for medium soil and soft soil compared to hard soil.

\section{CONCLUSIONS}

The effect of different soil types tends to be insignificant to the dynamic scale factor $\left(\mathrm{V}_{\text {static }} / \mathrm{V}_{\text {dynamic }}\right)$ for higher building. In contrast to lower buildings, soft soil tend to produce larger scale factor compared to hard soil. The increase of base-shear for Makassar city is about $34 \%$ and $103 \%$ for medium and soft soil compared to hard soil. The maximum displacement of building is correlated with the base-shear. The difference in building height does not affect the proportion of base-shear values for different soil types. The increase of beam negative moment is about 27\% to $39 \%$ in soft soil compared to hard soil, while for medium soil is about $8 \%$ to $14 \%$. The increasing pattern of beam positive moment is quite different (about $8 \%$ to $50 \%$ ), especially for 5 -stories building. The difference of longitudinal rebar area is directly proportional to the moment. The difference of stirrup rebar area is about $5 \%$ to $15.00 \%$ for medium and soft soil compared to hard soil. Demand capacity ratio of column increase about $10 \%$ to $35 \%$ for medium and soft soil compared to hard soil.

\section{ACKNOWLEDGMENT}

The authors gratefully acknowledge the partial financial support by Paulus Christian University of Indonesia, Makassar.

\section{REFERENCES}

Arfiadi, Y. and Satyarno, I. (2013) 'Comparison of Design Spectra for Big Cities in Indonesia Based on SNI 1726:2012 and SNI 1726:2002', in National Conference of Civil Engineering 7, p. S-299.

Cornelis, R., Bunganaen, W. and Tay, B. (2014) 'Comparative Analysis of Story Shear, Base Shear, Story Drift and Displacement Based on Earthquake 
Regulations SNI 1726-2002 and SNI 1726-2012', Civil Engineering Journa, 3(2), p. 205.

Faizah, R. and Widodo (2013) 'Analysis on Nominal Seismic Load for Multi-stories Building Using Dynamic Response Spectrum Method', in National Conference of Civil Engineering 7, p. S-201.

Hasan, A. and Astira, I. (2013) 'Comparative Analysis of Lateral Displacement for High Rise Building With Variations of Shear Wall Shape and Location in The Royale Springhill Residences Apartment Project', Civil Engineering and Environment Journal, 1(1), p. 47.

Imran, I. and Hendrik, F. (2010) Design of Earthquake Resistant Building for Reinforced Concrete Structures. Bandung: ITB Publisher.

Jingga, H., Suryanita, R. and Yuniarto, E. (2015) 'Building Structure Response Based on Indonesia Earthquake Spectra for Capitals on Sumatra Island', in Annual Civil Engineering 2015. Pekanbaru: ISBN: 978979-792-636-6, p. 111.
National Standardization Agency (2012) Earthquake Resistance Design Procedures for Structural and NonStructural Building. SNI 1726:2012. Jakarta.

National Standardization Agency (2013a) Minimum Load for Building Design and Other Structures. SNI 1727:2013. Jakarta.

National Standardization Agency (2013b) Structural Concrete Requirements for Building. SNI 2847:2013. Jakarta.

Soelarso, Baehaki and Novtikania, F. (2016) 'Comparative Analysis of Horizontal Drift On Earthquake Resistant Building Using Lateral Bracing Based on SNI 03-1726-2002 and SNI 03-1726-2012', Foundation Journal, 5(1), p. 24.

Sudarsana, K. and Yudha, M. E. (2014) 'Lateral Stiffness Effect on Dynamic Behavior of Low Rise Reinforce Concrete Building', in National Symposium RAPI XIII - 2014 FT UMS. ISSN 1412-9612, p. S-7. 
[This page is intentionally left blank] 